\title{
DEPENDENCE OF THE FORM OF THE ELECTRO- CARDIOGRAM UPON THE SITE OF MECHANICAL STIMULATION OF THE HUMAN VENTRICLES
}

\author{
BY B. S. OPPENHEIMER AND HAROLD J. STEWART
}

(From the Cardiographic Laboratory, Mt. Sinai Hospital and the Hospital of the Rockefeller Institute for Medical Research, New York)

(Received for publication July 6, 1926)

The relation of the form of the electrocardiogram to the site of stimulation in the ventricles still remains an open question, although patients have been studied from this point of view and many experiments on animals have been performed. Einthoven (1) in 1908 was the first to attempt to localize the site of origin of ventricular premature contractions by an analysis of patients' electrocardiograms. Even at the present time such localization cannot be made with any degree of accuracy in the human heart.

\section{LITERATURE}

Early investigations on the site of origin of ventricular premature contractions as ascertained by the electrocardiogram were abstracted in 1913 by Rothberger and Winterberg (2); we have used their paper in part as a guide for the following review of the literature. Einthoven (3) was the first to direct attention to the atypical complexes of ventricular premature contractions in man. Later, in 1908, he (1) was again the first to attempt the localization of the site of origin of ventricular premature contractions by studying the direction of the deflections in relation to the three axial leads. He employed Lead I to distinguish between the right and left sides, and the other two leads to differentiate proximity of the point of origin to base or apex. One year previously Kraus and Nicolai (4) had reported the results of their experiments on direct stimulation of the right and left ventricle of the dog's heart; they obtained oppositely directed diphasic complexes by the stimulation of these two chambers. For a time they considered such diphasic electrocardiograms as possibly due to hemisystoles, but subsequently abandoned this theory as untenable. Nicolai and Rehfisch (5) supplemented the previous work by showing that the greatest contrast in electrocardiograms resulted from the stimulation of the extreme right of the base as compared with that of the point 
farthest left of the apical region. They also found that every point stimulated gave a characteristic electrocardiogram more or less approaching in form the foregoing extreme types. In 1910, Kraus and Nicolai (6) divided the electrocardiographic curves of ventricular premature contractions induced experimentally in dogs' hearts into three fundamental types: type A, which resulted from stimulation of the apex; type $\mathrm{B}$, of the base; and type $\mathrm{C}$, polyphasic curves obtained by stimulating a central, more or less horizontal zone, situated about midway between apex and base. Nicolai (7) stressed the contrast between electrocardiographic curves from stimulation of base and apex, whereas Kahn (8) found the difference to depend upon which ventricle, right or left, had been stimulated. Subsequently Kahn (9) extended his experiments to the dorsal surface of the dog's heart, and found that in this region also, contrasting electrocardiograms depended not upon stimulation of base as compared with apex, but upon right as compared with left ventricle.

Rothberger and Winterberg (10) (1910-1911) found that there are exceptions to the general principle that ventricular premature contractions always yield anomalous complexes. They showed that stimulation of a point along the interventricular groove in a line connecting the anterior border of the right auricle with the apex, gave electrocardiograms which were normal in form. This observation, which has been confirmed, they explained by suggesting that from the point artificially stimulated the impulse traveled along abnormal pathways and reached both ventricles, causing them to contract simultaneously, just as they do as the result of a normal impulse conducted along normal channels. In 1915, as a result of the inability to localize with certainty the site of origin of ventricular premature contractions in man, the same authors (2) undertook to investigate the whole question again experimentally. For this purpose they selected dogs, and employed two leads, namely the standard Lead I and an anus-oesophagus lead which corresponds in a general way to standard Lead III. Their results are most easily seen by studying the diagram which illustrates their paper. Translating their language, for purposes of description only, into terms introduced by Lewis, one may say the following. On stimulation of a greater portion of the right ventricle, a concordant dextrocardiogram was obtained; that is to say, the first main deflection in both leads was directed upward. Similarly the greater portion of the left ventricle, that is most of the apex and dorsal surface, when stimulated yielded a concordant levocardiogram; that is to say, the first main deflection in both leads was directed downward. This result is what might be anticipated and is in harmony with the results of other investigators. But they found two unexpected exceptions to the general rule. In the first place, a basal portion of the left ventricle situated immediately beneath the left auricular appendix yielded an electrocardiogram which for descriptive purpose we may call a discordant dextrocardiogram; that is to say, the first chief deflection in Lead I was inverted, but in the anus-oesophagus lead was upright. In the second place, a somewhat similar exception was found in the right ventricle involving its apical and dorsal 
portions, which yielded curves of the discordant levogram type; that is to say, the chief deflection in Lead I was upright, but in the anus-oesophagus lead was inverted. The boundary on the ventral surface of the heart between the two areas yielding dextrocardiograms and levocardiograms respectively in the anusoesophagus lead, was not a sharp line, but a broad zone within which intermediate electrocardiograms with relatively small defiections were obtained. The location of this belt corresponds in general with that found by Kraus and Nicolai (6); it does not coincide with the interventricular groove, but is more horizontal in direction than the latter and is situated somewhat nearer the apex than the base. It is clear from these exceptions that the type of electrocardiogram obtained is not wholly dependent upon the particular ventricle, right or left, to which the artificial stimulus has been applied. Rothberger and Winterberg offer no final explanation for these unexpected results, and emphasize the fact that their findings cannot be applied to the human heart. Their findings are interesting and will be discussed after our results on the human heart have been given in detail.

Further experiments were carried out in this field by Lewis $(11,12)$. He concluded that when the surface of the ventricles is artificially stimulated, the excitation wave spreads radially in all directions, pierces the thickness of the ventricular wall, reaches the specialized conducting system, and thus is propagated at a greater velocity along the so-called conducting network to all parts, first of the corresponding ventricle, and ultimately of the opposite ventricle. Lewis reached this conclusion by stimulating a number of points in series on the surface of the two ventricles, recording the electrocardiograms and comparing the distance from the point stimulated to the underlying conducting network with the interval from the time of the stimulus to the first chief phase of the response. According to Lewis the "form of the electrocardiogram yielded by stimulating the surface of the ventricle seems to depend upon two chief factors, the relation of the point stimulated to the two networks of Purkinje, and its relation to the mass of ventricular muscle as a whole. Of these two factors the first exerts the dominant influence. The form naturally changes profoundly with the lead."

The experimental production of premature contractions in man by direct mechanical stimulation has heretofore been studied electrocardiographically only by August Hoffmann $(13,14)$. Like us, he studied patients who had been subjected to rib resection for empyema and in whom the heart on the left side was covered only by. the soft tissues. He stimulated the heart both with galvanic current and with a percussion hammer. Unfortunately the electrocardiographic curves he has published are so poorly reproduced that a satisfactory interpretation of them is impossible. He states, however, that the electrocardiogram yielded by the stimulation of various points was always the same, the chief deflection being inverted in Lead I, and upright in Lead III, and similar to that resulting from a right bundle branch lesion. There is an apparent contradiction in these two statements. He concluded that the mechanical stimulus on the surface of the ventricle was always propagated to the same specially susceptible centre, probably 
in the left branch of the Tawara system, and from there spread to the left ventricle along the specialized conducting system.

\section{SUBJECT OF OBSERVATIONS}

An opportunity has presented itself to investigate the subject in a patient whose ribs on the left side had been removed in the course of a modified Estlander operation for empyema some twenty-five years before. Over the left lateral chest wall the contractions of the auricles and ventricles are distinctly seen and felt though the soft tissues. By appropriate mechanical stimulation premature contractions can be elicited from either ventricle or auricle. We are reporting in this paper the results obtained by such artificial stimulation, more particularly of the ventricles.

Clinical history. H. L. is a man aged 60 years. He was admitted to the Mt. Sinai Hospital on June 1st, 1925. ${ }^{1}$ During the favorable months of the year he exhibits himself as "The Human Heart Wonder." The history and physical examination in so far as they concern our study is as follows. The family history is unimportant.

Past history. Twenty-five years ago he suffered from an attack of pneumonia which was followed by left hydropneumothorax and subsequently by empyema of the left pleura. One year after this illness a simple thoracotomy was performed for the relief of empyema; this was followed by a second operation in which resection of the fourth, fifth, sixth, and seventh ribs of the left side was performed; later at a third operation the remaining ribs of the left side are said to have been resected. The sinus of the empyema wound drained for one year. Six years ago he had an attack of influenza. Since then he has been the subject of chronic heart block. There has been only one attack of syncope in this connection. He was readmitted to the Hospital for further study on January 1st, 1926 and was discharged on February 23rd, 1926.

Physical examination. The patient was very emaciated. His weight was 96 lbs. The left chest wall was sunken as a result of the resection of the lateral portions of the second to eighth ribs. Regeneration of the ribs had not occurred. There was marked scoliosis of the spine, with convexity to the left. The left hypochondrium bulged prominently. Anteriorly over the left chest wall auricular contractions were distinctly seen over an area about $2 \mathrm{~cm}$. in diameter, opposite to and to the left of the second costal cartilage. The auricular sounds were audible over this area. Very forcible ventricular contractions could also be seen and felt through the overlying soft tissues from the level of the upper border of the third

\footnotetext{
${ }^{1}$ We wish to thank Dr. S. Calvin Smith for his courtesy in referring this patient
} to us. 
rib to the level of the stump of the sixth rib. Cinematographs were taken to show these motions. A systolic murmur was heard over the area occupied by the ventricles. The auricles and ventricles were contracting independently. There was an occasional spontaneous ventricular premature contraction. Both auricular and ventricular premature contractions could be artificially induced with a percussion hammer by mechanical stimulation of the overlying skin. Mechanical stimulation of the auricles gave the patient a "stinging sensation inside the chest," but there was no sensation whatever when he was tapped over the region of the ventricles. There was marked arteriosclerosis of the radial and brachial arteries. The systolic blood pressure was $170 \mathrm{~mm}$. of mercury and the diastolic $75 \mathrm{~mm}$. The percussion note over the right chest was hyperresonant. There was bronchovesicular breathing at the right apex. In the axillary region over the collapsed lung the breath sounds and many moist râles were heard. In fluoroscopic examinations of the chest ${ }^{2}$ the left ventricle was not seen distinctly but was obscured by the spine and the ends of the resected ribs. It was seen only slightly on deep inspiration. Two or three movements of the auricles occurred to one of the ventricles. The right border showed faint auricular contractions in the intervals between systoles of the right ventricle. The right ventricle showed a slow contraction of wide amplitude, followed by a gradual relaxation, the shadow receding to the right and showing the auricular effect. An x-ray photograph of the chest showed extreme collapse of the left lung and pleura. The heart was displaced toward the right side. The structural details of the left lung were obscured by the thoracic deformity.

Diagnosis. There was chest deformity due to a thoracoplastic operation, heart block of six years' duration of unknown cause, arteriosclerosis, and arterial hypertension (wide pulse pressure).

\section{METHODS}

It seemed possible that information might be gained by studying in this patient the relation of the form of ventricular premature contractions to the location of the point stimulated. The heart to the left of the sternum was covered by only the pericardium and soft tissues. It was possible to elicit ventricular premature contractions by tapping mechanically on the external chest wall overlying the heart, the mechanical stimulus being transmitted to the ventricular surface. We obtained electrocardiograms of ventricular premature contractions by stimulating eight points on the chest wall overlying the heart and have studied the resulting curves. Four points were selected which

${ }^{2}$ We wish to thank Dr. Harry Wessler for making the fluoroscopic and $\mathrm{x}$-ray examinations in this patient. 
were as far to the left as possible; four other points were chosen which lay along the left sternal margin as far as possible toward the midline. These eight points were marked with silver nitrate. Small squares of court plaster were placed over the points when the chest was photographed (fig. 1). They were numbered 1 to 8 in a clockwise direction, beginning at the upper left hand. All of them lay over the ventricular surface of the heart. In as much as complete heart block was present (fig. 1, point no. 9) independent auricular and ventricular contractions could be seen distinctly so that the dividing line between auricles and ventricles could be located without difficulty. Point no. 9 was just medial to the left nipple, over the auricular portion of the heart.

A triangular shaped rubber reflex hammer was used to tap the points. The patient lay flat in bed while observations were being made. The three standard leads of the electrocardiogram were photographed simultaneously by three galvanometers during mechanical stimulation of the heart. The arrangement of the galvanometers and the precautions taken in making the simultaneous electrocardiograms were those described by Cohn (15). The shadow of an electromagnetic signal indicated on the electrocardiographic record when the chest was tapped. One complete series of observations was made while the patient was lying flat; and a second, when he lay on his right side so that points nos. 1 and 4 could be tapped again. By this manoeuver we thought, provided the heart were freely movable, other points on the left ventricle would be exposed for stimulation. In a third series the patient was turned so that he lay on his left side and points nos. 5 to 8 tapped. The plan was to expose if possible other points on the right ventricle. Electrocardiograms of many ventricular premature contractions were obtained from each point during each series of observations. The observations were repeated several times on the same day, on successive days, and also after an interval of several months. It is important to state that the same results were always obtained on tapping the same point.

THE DATA

Premature contractions having the ventricular form were elicited from points nos. 1 to 8 (fig. 1). The ventricular premature contrac- 


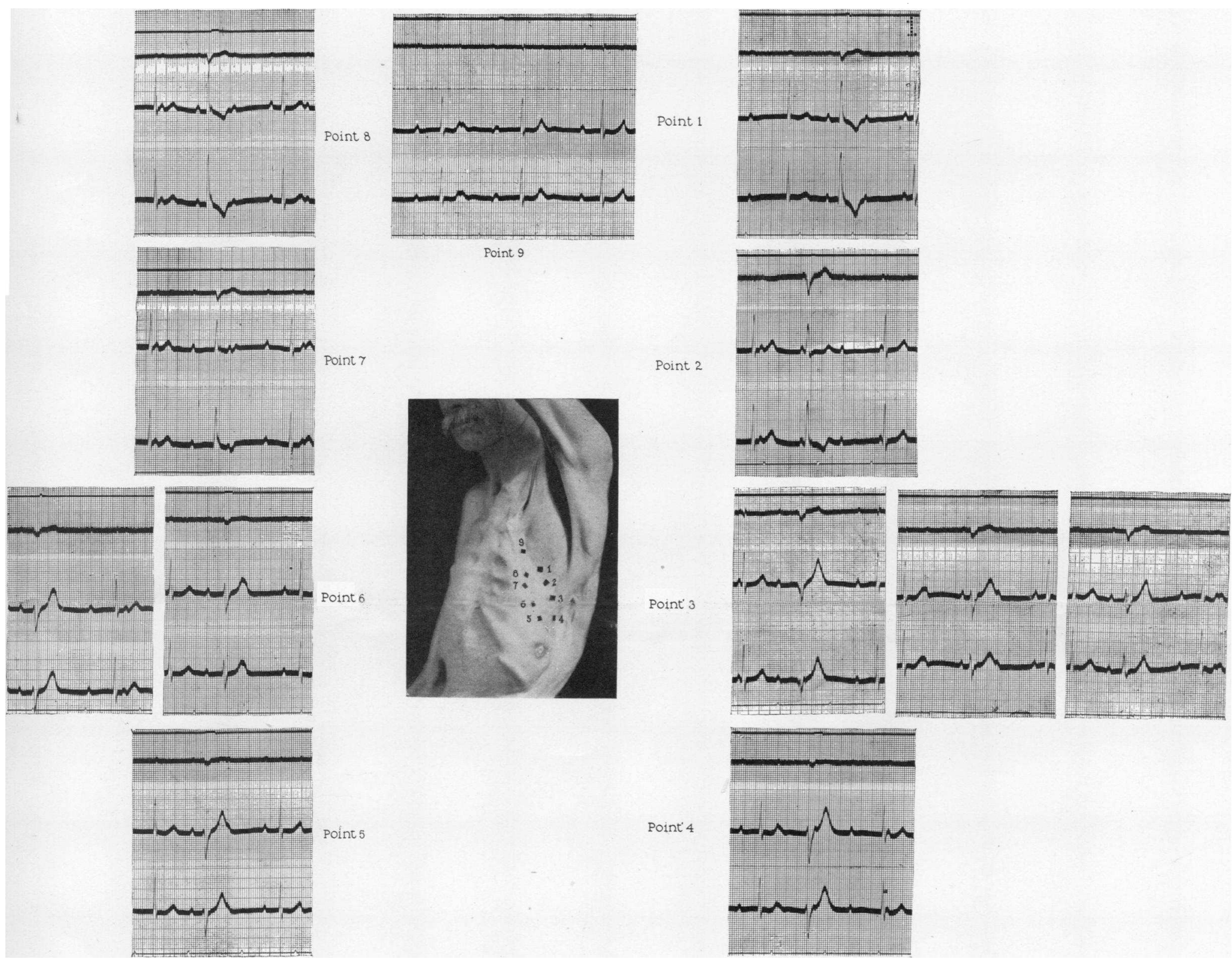

FIG. 1. In the center of this figure is reproduced a photograph of the chest of the patient to show the position of points nos. 1 to 9 . Points nos. 1 to 8 lie over the ventricular and point no. 9 over the auricular part of the heart. On the right are reproduced typical electrocardiograms derived by stimulating each of the points on the extreme left of the patient's chest. On the left are reproduced representative electrocardiograms derived by stimulating each of the points along the sternal margin (points nos. 5 to 8 ). At the top is shown an electrocardiogram obtained by stimulating point no. 9 over the auricles. Points nos. 5 to 8 lie along the left sternal margin, point no. 5 being in the fifth interspace, point no. 6 on a level with the upper half of the stump of the fifth rib, point no. 7 in the fourth interspace, and point no. 8 on a level with the upper half of the stump of the fourth rib. Points nos. 1 to 4 are in the position indicated in the photograph. The distances of points nos. 1 to 8 from the midsternal line are as follows, beginning with point no. 1: 8.7, 11.0, 11.5, 13.5, 11.0, 9.3, 8.0 and $7.2 \mathrm{~cm}$. Point no. 9 has the position indicated. The electrocardiograms from above downward read Leads I, II and III. The three leads are taken simultaneously by three galvanometers. Divisions of the ordinates equal $10^{-4}$ volts. Divisions of the abscissae equal 0.04 of a second. The record of the electromagnetic signal at the top of each curve indicates when the point was tapped. The original curves are sharply contrasted black and white; no half tones are lost by the method of reproduction here used. The electrocardiograms are reduced to one-third of their natural size. 
tions were of three varieties; first, that in which spiked complexes were directed upward in Lead III; ${ }^{3}$ second, that in which spiked complexes were directed downward in Lead III; and third, that of a transitional type with spiked complexes which were diphasic. Stimulation of the same point, with the exception of points nos. 3 and 6, always yielded the same type of premature contraction. From these points transitional types were obtained as well as types having spiked complexes directed upward in Lead III and downward in Lead III. From points nos. 1 and 2 ventricular premature contractions were obtained in which the major spiked deflection was upward in Lead III (fig. 1). From point no. 3, three varieties of ventricular premature contractions were derived, namely, (1) those in which spiked deflections were similar in direction to the premature contractions from points nos. 1 and 2; (2) those exhibiting spiked downward deflections in Lead III; and (3) a transitional variety in which were seen deflections directed both upward and downward in Lead III. From points nos. 4 and 5 premature contractions were obtained the major deflections of which were directed downward in Lead III. From point no. 6, ventricular premature contractions were derived in which the spiked deflections were directed downward in Lead III, as well as a transitional variety with diphasic spiked deflections. From points nos. 7 and 8 , only ventricular premature contractions with spiked complexes upward in Lead III were obtained (fig. 1).

Auricular premature contractions were elicited on tapping point no. 9 (fig. 1). They were identified as premature contractions in the first place because they occurred coincidently with the signal; in the second place because of their prematurity, and in the third place because their form differed from that of normal auricular complexes, in that the induced ones were diphasic. Ventricular responses naturally did not follow the auricular premature contractions.

Monocardiograms were constructed of every variety of ventricular premature contraction obtained from each of the 8 points (fig. 2). The method described by Mann (16) was used in plotting these curves. The amplitudes of the ventricular complexes were measured by means of a Lucas comparator at convenient points in the cardiac cycle.

\footnotetext{
${ }^{3}$ The ventricular deflections in Lead I were so small in this patient that the consideration of them may be neglected.
} 


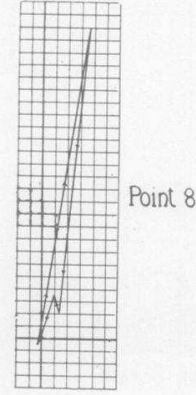

Point 1
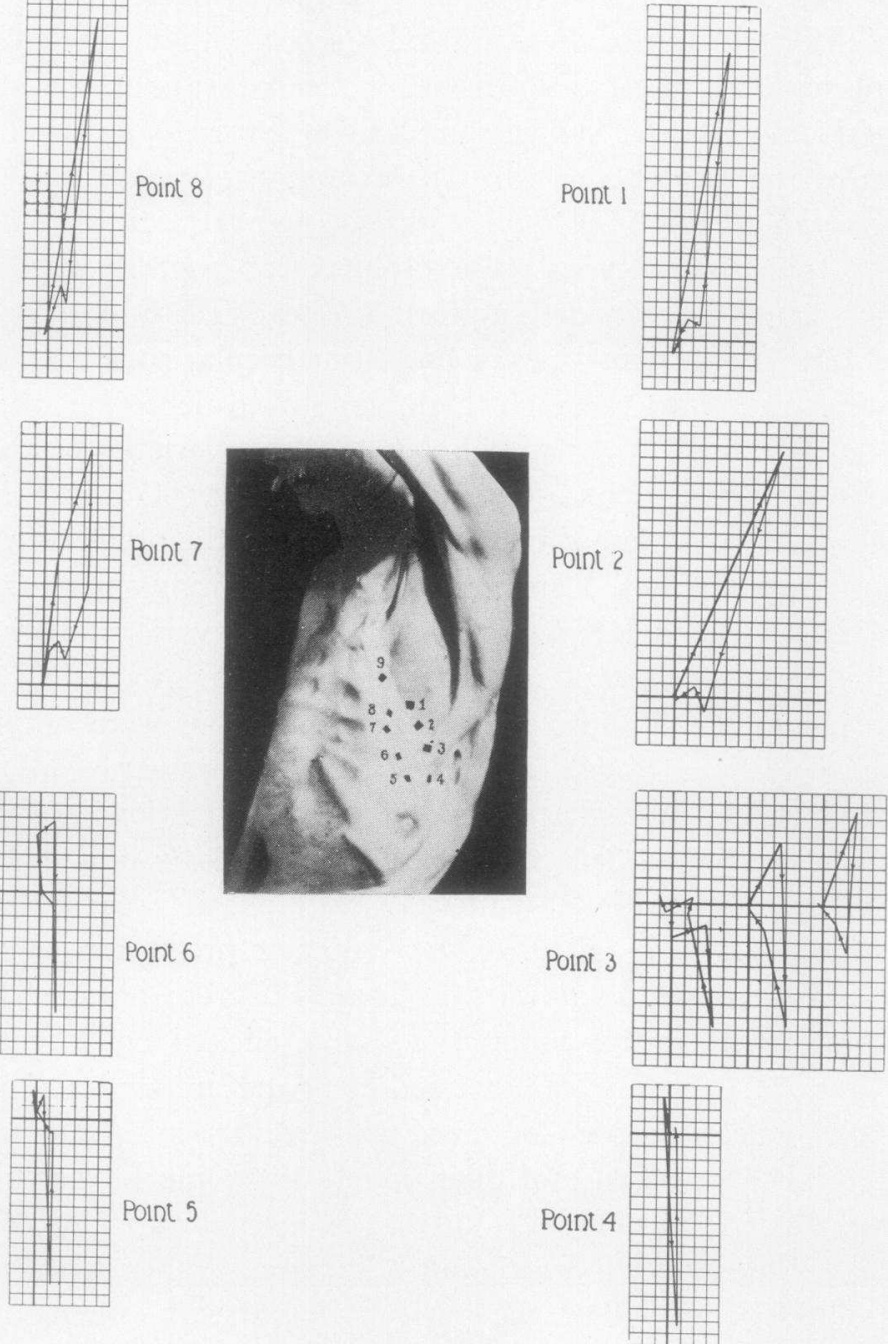

FIG. 2. In this figure are presented monocardiograms derived from the ventricular premature contractions reproduced in the electrocardiograms in figure 1, points nos. 1 to 8 . The position of any monocardiogram in this figure corresponds with that of the complex from which it was derived in figure 1. The location of the points on the chest wall is shown in the photograph in the centre of the figure. Natural size. 
Since in these records the three leads of the electrocardiogram were photographed simultaneously they were in phase and the measurements required no trial and error adjustment to bring about an arrangement such that Lead II equals Lead III plus Lead I. The monocardiograms derived from the ventricular premature contractions

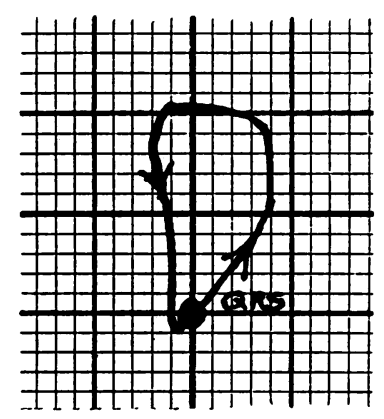

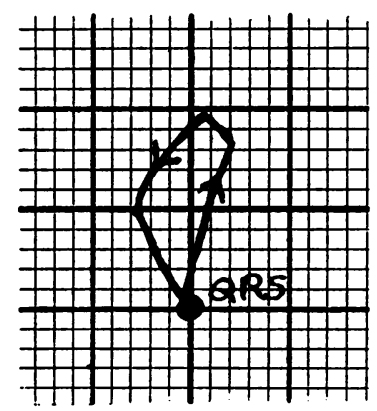

Fig. 3

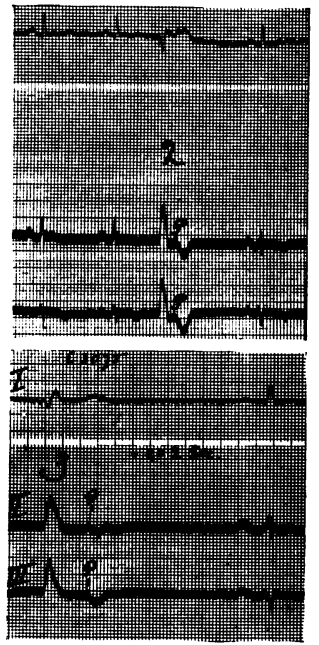

FIG. 4

FIg. 3. In this figure are presented the monocardiograms derived from the ventricular premature contractions reproduced in figure 4 . The upper monocardiogram is derived from complex no. 2 , figure 4 , and the lower curve from complex no. 3. Natural size.

FIg. 4. In this figure two electrocardiograms from Prof. Einthoven's patient are reproduced (Leads I, II and III from above downward). The ventricular premature contraction in both instances was obtained by tapping over the right ventricle. The three leads are taken synchronously. Divisions of the ordinates equal $10^{-4}$ volts. In the upper curves (2) divisions of the abscissae equal 0.04 of a second; in the lower curves (3) 0.02 of a second. The original curves are sharply contrasted black and white; no half tones are lost by this method of reproduction. The electrocardiograms are reduced to one-third of their natural size. 
in this series are of three types (fig. 2). Those from points nos. 1, 2, 7 and 8 are situated in the upper right hand quadrant from the starting point, the "centre of negativity" traveling in a clockwise direction; those from points nos. 4 and 5 lie in the lower right hand quadrant for the most part and the "centre of negativity" travels in a counterclockwise direction. Those from points nos. 3 and 6 are sometimes in one quadrant, sometimes in the other, and if constructed from ventricular premature contractions of the transitional variety they lie in both quadrants (fig. 2). Monocardiograms do not however aid us in the interpretation of the data from the point of view of the origin of the premature contractions, although they help us to visualize the progress of events during the course of the various cardiac cycles. The monocardiograms (fig. 3) derived from the right ventricular premature contractions from Professor Einthoven's patient (fig. 4) (see page 598) are similar in general to those obtained by us from point no. 8 in our patient (fig. 2).

Attention is called to the observation that in the electrocardiograms the R-R interval from the induced ventricular premature contraction to the following restored cycle is about 0.08 of a second longer than the normal R-R interval in this patient. The delay is probably due to the time it takes the artificial stimulus to pass through the ventricular wall.

\section{DISCUSSION}

Ventricular premature contractions may theoretically have arisen in any one of four ways: (1) from the right ventricle, (2) from the left ventricle, or (3) from neither ventricle regarded as a lateral half of the heart, but rather as arising from the base or (4) from the apex, in this way assuming a division of the heart in cephalo-caudal halves. According to the first view, major deflections directed upward in Lead III are derived from the right ventricle (VPCR); according to the second, they are likewise directed upward in Lead III, but are now believed to be derived from the left ventricle (VPCL). There are others who think that the form of ventricular premature contractions in which the major deflection is upward in Lead III is dependent not upon derivation from either the right or left ventricle, but rather upon an origin (3) from the base or (4) from the apex of the heart. 


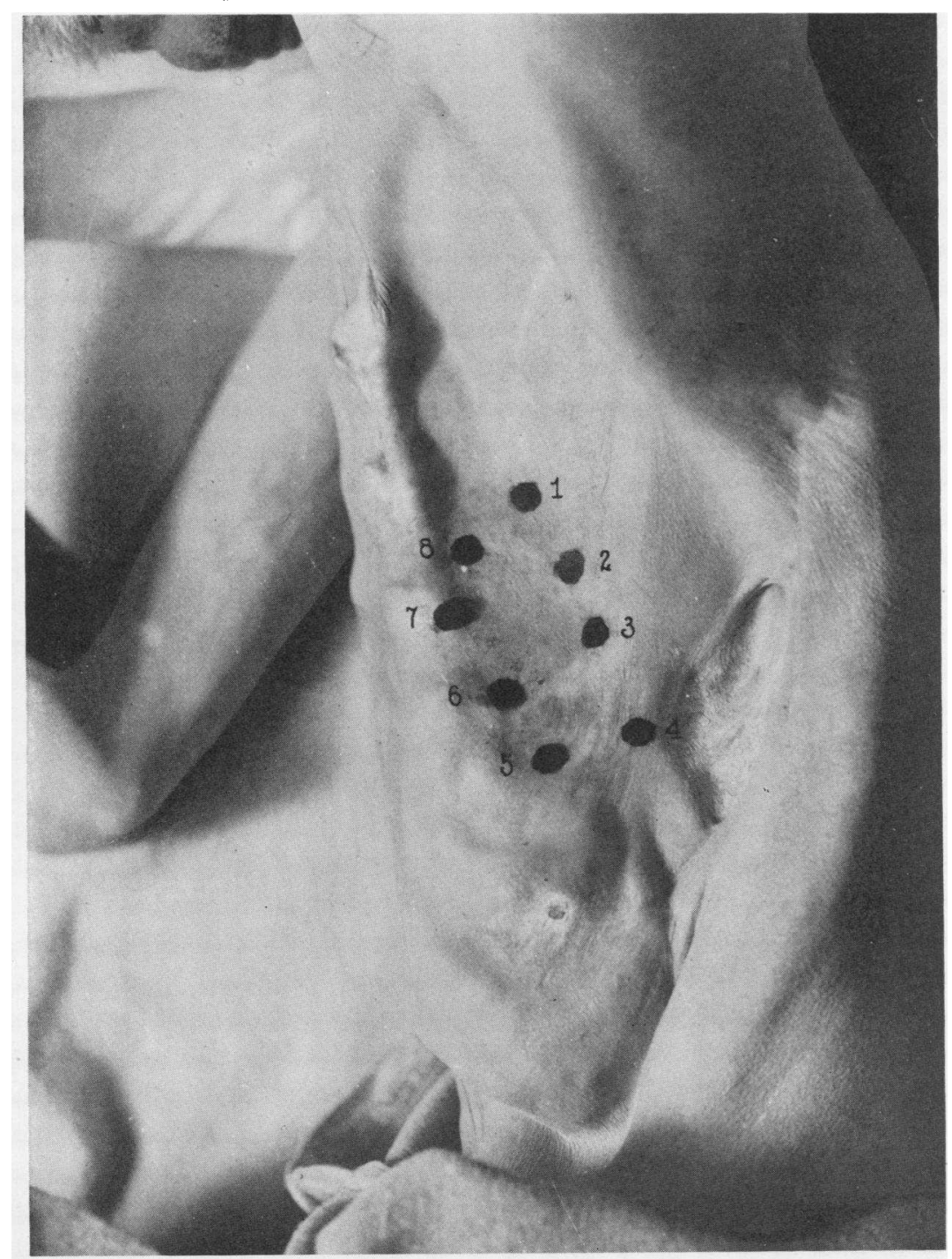

FIG. 5. In this figure is reproduced a photograph of the left side of the chest of the patient. The patient was lying down. The absence of a bony chest wall to the left of the sternum is seen. The positions of points nos. 1 to 8 are indicated. 
Lewis (12) thought that it was unwise to transfer the conclusions from his experiments in dogs to the form of ventricular premature contractions arising in the human heart, because of differences in distribution of the conduction system and in the relation of the heart to the chest wall in the two species. The ideal method in which to study the problem would be to stimulate the fully exposed heart. One could then force beats from base or apex, from right and left ventricle. The correlation between beat and curve could then be made directly as in the case of the dog, not inferentially as is necessary in studies of the type we are now reporting. Since the heart in this patient was not exposed to view we are unable to state the location of all the points stimulated. The problem then is this; is a given curve representative of an impulse originating in one of the ventricles or has its form an apex-base significance? Obviously a decision can be reached if the issue were based on a right-left ventricle difference, for here there is an anatomical division; in the apex-base case, there is none. It is of no value to approach the apex-base problem until proof is at hand to show that it is not a two-ventricle problem. It is necessary therefore to solve the two-ventricle problem first. This should be possible, provided it is practicable to ascertain the position of the anterior interventricular groove. If it turns out to be impossible to do this convincingly, then it is possible to do no more than to present the data which we have found as probabilities affecting the twoventricle relation; the apex-base problem must remain in abeyance until more suitable methods become available.

Two of the points can however be located without much doubt. Point no. 8 lay over the right ventricle near the base (figs. 1 and 5); point no. 4 must have lain over the left ventricle. Point no. 8 was a short distance from the midsternal line. (The distance from the midsternal line curving around the stump of the rib to this point was $7.2 \mathrm{~cm}$.) From a study of illustrations of the heart in anatomical atlases and also as the result of manipulation of gross anatomical specimens to learn what positions could be assumed by the heart on rotation, we concluded that it was hardly possible for the left ventricle to lie under this point. Point no. 4 must have been over the left ventricle (figs. 1 and 5). It was to the left of the point of maximal impulse and was $13.5 \mathrm{~cm}$. from the midsternal line in the fifth inter- 
space. The chest began to curve posteriorly here so that this point must have been on the left lateral border of the heart. It is not possible to think of the heart in a position in which the right ventricle could have assumed this location. We can be fairly certain then that point no. 8 lay over the right ventricle near the base and point no. 4 over the left ventricle near the apex.

If we interpret this patient's curves according to the right-left ventricular origin theory, the premature contractions obtained from points nos. 1, 2, 7 and 8 were derived according to the first theory from the right ventricle, those from points nos. 4 and 5 were derived from the left ventricle, while those from points nos. 3 and 6 were derived from an intermediate position. In accordance with the second theory, still on the basis of the two-ventricle theory, those premature contractions from points no. 1, 2, 7 and 8 were derived from the left ventricle, and those from points nos. 4 and 5 from the right ventricle and those from 3 and 6 would again be transitional. According to the apex-base theory of origin, the curves obtained from points nos. $1,2,7$ and 8 would be basal in origin, those from points nos. 4 and 5 apical, and those from points nos. 3 and 6 transitional. The fourth possible position, that curves from points nos. 1, 2, 7 and 8 are apical in origin, is held by no one.

In this patient there was a sharp and constant zone on the surface of the chest and therefore on the heart lying beneath, above which ventricular premature contractions of one form were obtained and below which those of an opposite form, while along the zone those of a transitional type were elicited. A line drawn from point no. 3 to point no. 6 approximately marks the zone from which the transitional curves were obtained (fig. 1). The problem now narrows itself to this question: could this zone cover the position of the interventricular septum? If it can, points nos. 1, 2, 7 and 8 are obviously located on the right ventricle; and points nos. 4 and 5 on the left; the transitional points nos. 3 and 6 , on intermediate positions too difficult to assign under these conditions.

We have attempted to arrive at information on this point in several ways. Physical examination yielded no information. The patient's heart was next subjected to careful fluoroscopic examination, but as was to be expected the interventricular septum could not be located. 
Small lead discs were then placed on the points nos. 1 to 8 , and $x$-ray photographs were made of the chest. This procedure likewise yielded no useful information because all of the lead markers were projected almost in the same sagittal plane in the postero-anterior view and because the deformity of the chest confused the shadow of the heart in a lateral view. Since none of these examinations were of assistance in deciding upon the position of the interventricular septum, we turned

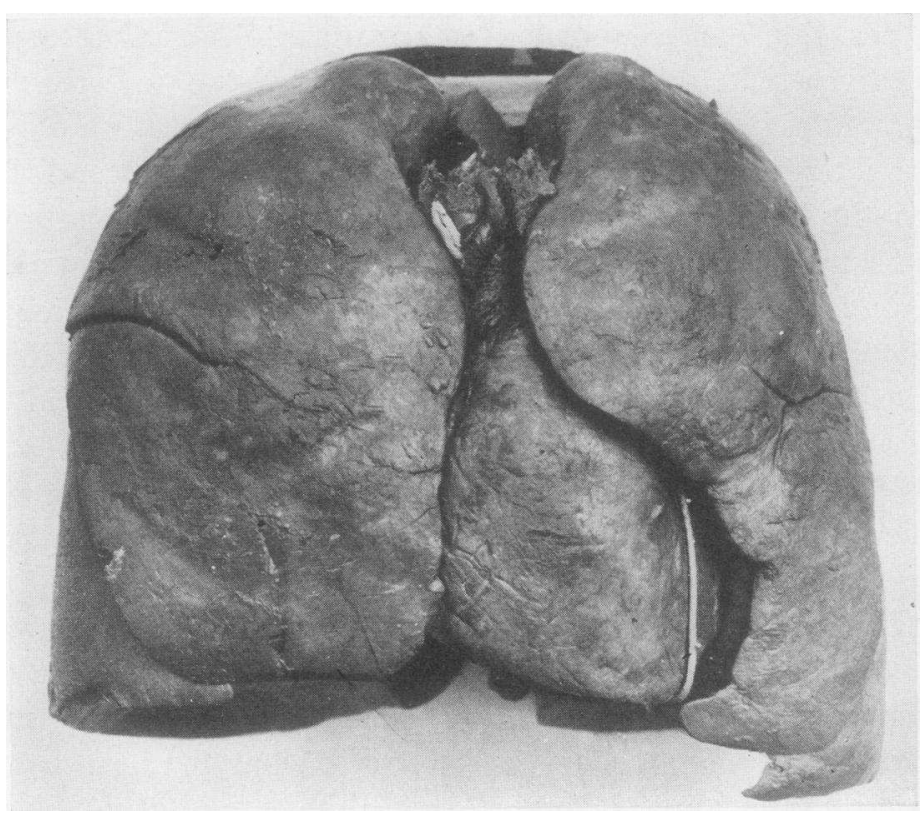

FIG. 6. In this figure is presented a photograph of a normal heart and lungs removed from the chest en masse after thorough hardening. The view is anterior. The object is to show the position of the interventricular sulcus along which a white wire was placed. The left lung is to the reader's right.

to the examination of gross anatomical specimens. We were fortunate in finding a specimen which was suitable for our purpose. ${ }^{4}$ The thoracic contents of a cadaver which was thoroughly fixed and hard-

${ }^{4}$ The specimen was loaned to us by Dr. Adolf Elwyn of the Department of Anatomy, College of Physicians and Surgeons, Columbia University, New York. We wish to thank Dr. Elwyn for his courtesy in placing this specimen at our disposal. 
ened in situ was removed from the chest en masse. There appeared to be no deformity in the position of the heart nor in its relation to the lungs (fig. 6). A white wire was placed along the interventricular sulcus, in order to give the approximate position of the interventricular septum. Instead of photographing the specimen as one would normally and naturally do from in front, the optical axis being antero-

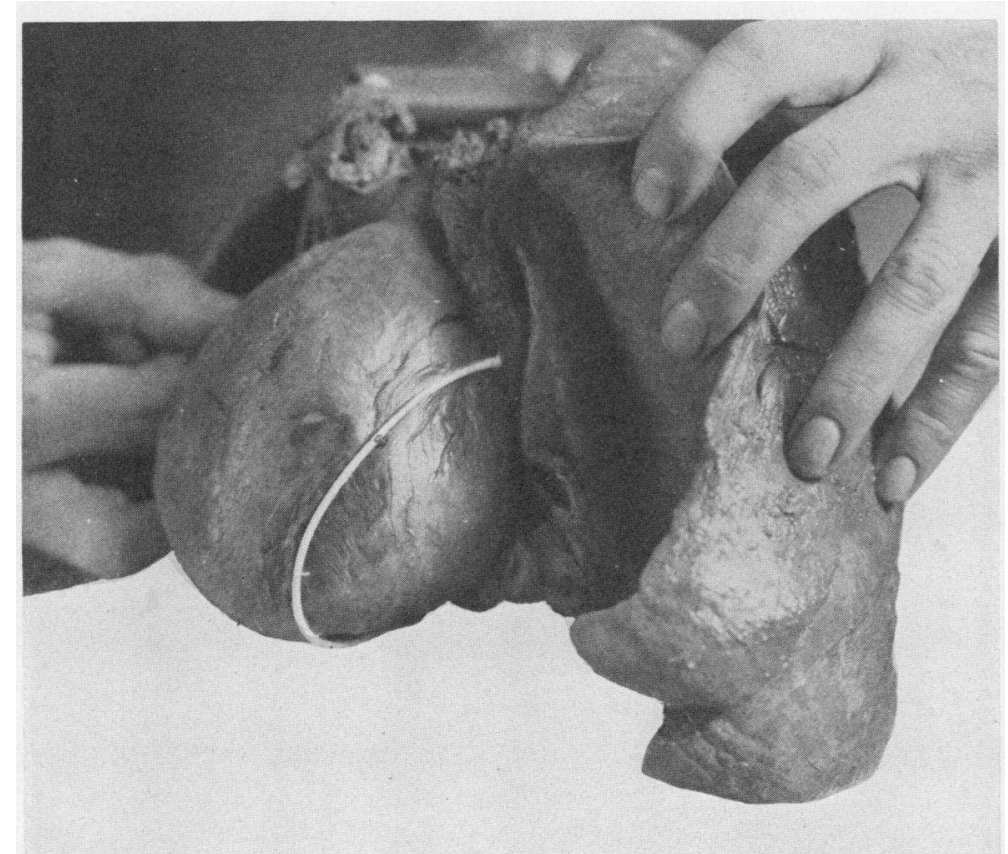

Fig. 7. A left lateral view of the left normal heart and lungs shown in figure 6 is reproduced in this figure. The left lung is held aside in order to photograph the position of the interventricular sulcus, indicated by the white wire. Same size as figure 6 .

posterior through sternum and vertebral column, we shitted the camera so that the optical axis was perpendicular to a tangent which touched the chest at about the anterior axillary line (fig. 7). We did this on the assumption that the heart had been dislocated and were desirous of treating it as if it were in the normal position. Having created conditions which simulated the normal, we rotated the heart on its own long axis. The position which the interventricular sulcus takes 
before rotation of the heart is best seen in the photograph (fig. 7). Rotation of the heart within limits which might be expected to occur clinically did not alter materially the position of the interventricular sulcus. In drawing aside the left lung in order to photograph the heart from the side we were duplicating the condition existing in this patient, in whom there was no lung tissue in this region.

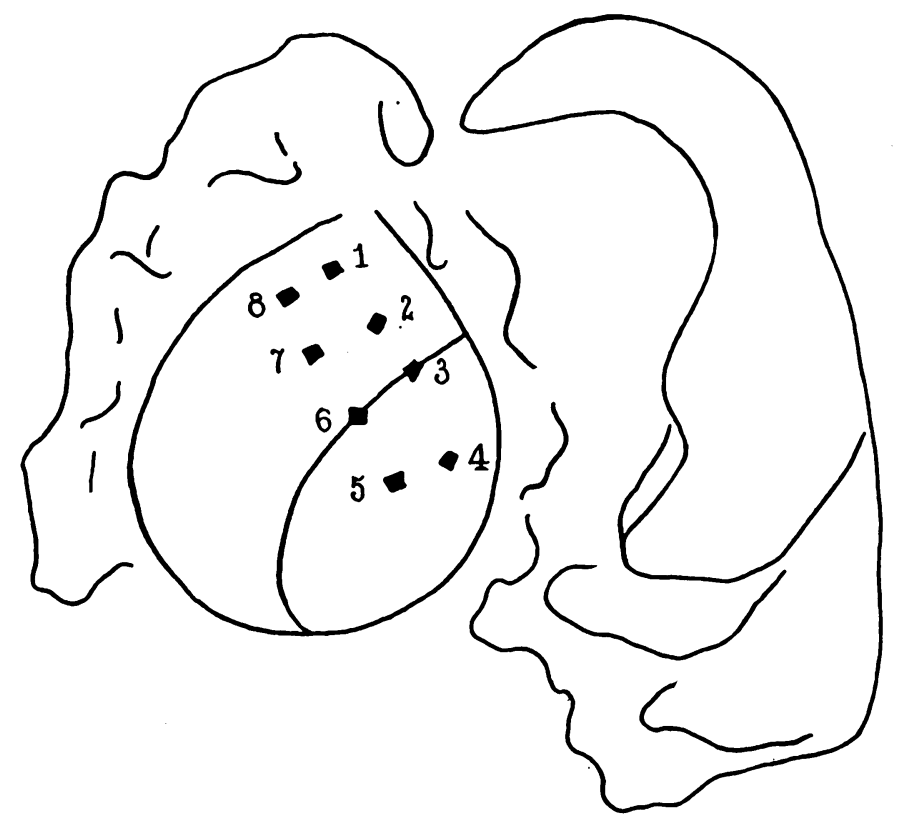

FIG. 8. In this figure is shown a drawing made by combining figures 1 and 7 in the following manner. A tracing of the heart outline is made from figure 7, on which is indicated the position of the interventricular sulcus. A tracing was also made from the photograph of the chest in figure 1 (before reduction) to give the positions of points nos. 1 to 8 with reference to one another. This tracing was then superimposed on the tracing of the heart in the manner seen in this figure. The interventricular groove passes through points nos. 3 and 6 . Same reduction as in figures 6 and 7 .

Having established in a photograph the position of the interventricular groove in this anatomical specimen (fig. 7), we attempted to see what positions points nos. 1 to 8 indicated on the chest wall would take with reference to it. The heart outline showing the 
position of the interventricular groove was traced on paper. A similar tracing was made of points nos. 1 and 8 from the photograph of the chest (fig. 1). The second tracing was then superimposed on the first (fig. 8). Points nos. 1, 2, 7 and 8 lie on the right ventricle, points nos. 4 and 5 on the left ventricle, and points nos. 3 and 6 in the neighborhood of the interventricular groove (fig. 8). Since the points nos. 1, 2, 7 and 8 lay on the right ventricle and yielded upward deflections in Lead III, ventricular premature contractions having this form are right ventricular in origin; similarly ventricular premature contractions having downward deflections in Lead III are left ventricular in origin. We are led then to a conclusion based on a rightleft ventricular origin of the premature contractions. This, it may be recalled, is the generally accepted view. This conclusion which can be derived from this method of procedure is however not justified for the position of the interventricular groove may have been different in this patient's heart from that in the normal specimen. There is however a strong probability that his heart was in the normal position, for it was practically fixed in the chest as is indicated by the small shift of the electrical axes on changing the patient's position (Dieuaide (17)). Nor did the position of the heart alter sufficiently lying on his right and then on his left side to change the form of the premature contractions derived from points nos. 1 to 8 .

The view that ventricular premature contractions are left ventricular in origin in which the main deflections are directed upward in Lead III and the reverse, right, can not be maintained in view of our data. There can be little doubt that point no. 8 was over the right ventricle near the base and point no. 4 over the left near the apex. The form of the ventricular premature contractions which we obtained from these points makes such an interpretation impossible. This view is confirmed by the interpretation of an electrocardiogram from a patient which Professor Einthoven has kindly allowed us to use ${ }^{5}$ (fig. 4). In this patient the greater part of the sternum and ribs was removed by an operation following an accident. Professor Einthoven was able to induce ventricular premature contractions by mechanical stimulation of an area which was over the right ventricle. The form of the

\footnotetext{
${ }^{5}$ We wish to thank Professor Einthoven for his kindness in placing this electrocardiogram at our disposal.
} 
ventricular complexes which he obtained was essentially the same as that of the ventricular premature contractions which we elicited from point no. 8 in our patient (fig. 1).

The significance of the experiments of Rothberger and Winterberg in this connection should be reviewed. It is possible, although improbable, that we repeated in the human subject that part of their experiment in the dog in which they stimulated a series of points on the left ventricle in a line from base to apex. On stimulating the base, they obtained ventricular premature contractions in which the first main deflection was inverted in Lead I and upright in Lead III; on stimulating the apex, they obtained ventricular premature contractions in which the first main deflection was inverted in both leads; and on stimulating an intermediate zone, they obtained premature contractions transitional in type. The fact that our curves resemble in direction the three types yielded by the left ventricle of the dog, makes it necessary to consider whether our case and their experiments are analogous, that is to say, whether we also stimulated points on the left ventricle only, and that stimulation of the base of the human left ventricle yields ventricular complexes in which the first main deflection is also upright in Lead III. Against this interpretation is the fact that in Einthoven's patient stimulation of the right ventricle yielded ventricular premature contractions identical with ours in which the first main deflection is upright in Lead III (fig. 4). The question remains undecided, however, whether both left and right ventricles yield similar complexes at their bases, although it is improbable that they should do this.

From the data which we have accumulated, we can not conclude that the base-apex interpretation is correct; neither can we conclude that it is incorrect. When we stimulate a region of the heart which is right ventricle we obtain in the electrocardiogram complexes which are generally identified as being right ventricular in origin (VPCR); but this region undoubtedly is also the base. When we stimulate an area which is left ventricle we obtain ventricular permature contractions which have the form generally accepted as being derived from the left ventricle (VPCL); and this area undoubtedly is also the apex. In a region between these two areas and in a direction running almost transversely, ventricular premature contractions of a transitional 
type are obtained. If it were not for the light which we have been able to throw on the location of the interventricular groove, we should be in a dilemma. If we are correct in assigning its location in relation to the points of stimulation, we have no choice except to adhere to the two-ventricle interpretation of this problem. We deal with an obvious correlation of anatomical with the electrocardiographic facts. A doubt exists only in the justice of our inference from the similarity of the facts in this case and in the anatomical specimen. But until the reasons for doubt increase or become intensified, there is no adequate ground for turning to the apex-base theory. It seems best therefore to continue to designate ventricular premature contractions when the main deflections in Lead III are erect as VPCR, and VPCL when in Lead III they are inverted.

\section{SUMMARY AND CONCLUSIONS}

From a patient in whom it was possible to stimulate the ventricles of the heart mechanically we have obtained electrocardiograms of artificially induced ventricular premature contractions. The premature contractions fall into three groups on the basis of their form: those having upward deflections in Lead III, those having downward deflections in Lead III, and those having diphasic deflections in Lead III. Although it is not possible to identify which portions of the ventricles lay beneath all of the points stimulated, we are nevertheless reasonably certain that when a point definitely over the right ventricle was stimulated the spiked deflections in the electrocardiogram of the premature contractions were upright in Lead III (VPCR) and inverted when the point stimulated was over the left ventricle (VPCL). To retain the terminology which is in current use seems therefore justified. To consider ventricular premature contractions the main deflections of which are upright in Lead III as originating in the right ventricle, and those the first main deflections of which are inverted in Lead III as originating in the left ventricle, is also justified.

\section{BIBLIOGRAPHY}

1. Einthoven, W.: Arch. f. d. ges. Phys., 1908, cxxii, 579. Weiteres ueber das Elektrokardiogramm. 
2. Rothberger, C. J., and Winterberg, H.: Arch. f. d. ges. Phys., 1913, cliv, 571. Studien ueber die Bestimmung des Ausgangspunktes ventrikulärer Extrasystolen mit Hilfe des Elektrokardiogramms.

3. Einthoven, W.: Arch. internal. de phys., 1906, iv, 132. Le Télécardiogramme.

4. Kraus, F., and Nicolai, G. F.: Berl. klin. Woch., 1907, xliv, 765 and 811. Ueber des Elektrokardiogramm unter normalen und pathologischen Verhältnissen.

5. Nicolai, G. F., and Rehfisch, E.: Zentralb. f. Phys., 1908, xxii, 57. Ueber des Elektrokardiogramm des Hundeherzens bei Reizung des linken und rechten Ventrikels.

6. Kraus, F., and Nicolai, G. F.: Das Elektrokardiogramm des gesunden und kranken Menschen. Leipzig, 1910.

7. Nicolai, G. F.: In Nagel, W., Handb. d. Phys., Braunschweig, 1909, i, 822. Versuche die Richtung der Erregungswelle zu bestimmen.

8. Kahn, R. H.: Zentralb. f. Phys., 1909, xxiii, 444. Ueber das Elektrokardiogramm künstlich ausgelöster Herzkammerschläge.

9. Kahn, R. H.: Zentralb. f. Phys., 1910-11, xxiv, 728. Ueber anomale Herzkammerelektrogramme.

10. Rothberger, C. J., and Winterberg, H.: Zentralb, f. Phys., 1910-11, xxiv, 959. Zur Kenntnis des Elektrogrammes der ventrikulären Extrasystolen.

11. Lewis, Thomas: Phil. Trans. Royal Soc., 1916, B., ccvii, 278. The Spread of the Excitatory Process in the Vertebrate Heart.

12. Lewis, Thomas: The Mechanism and Graphic Registration of the Heart Beat. 3rd Ed., London, 1925, 218.

13. Hoffmann, A.: Med. Klin., 1913, ix, 2025. Ueber künstliche Auslösung von Arhythmien am gesunden menschlichen Herzen.

14. Hoffmann, A.: Die Elektrographie. Wiesbaden, 1914, 121.

15. Cohn, A. E.: Heart, 1922, ix, 311. An Investigation of the Relation of the Position of the Heart to the Electrocardiogram.

16. Mann, Hubert: Arch. Int. Med., 1920, xxv, 283. A Method of Analyzing the Electrocardiogram.

17. Dieuaide, F. R.: Arch. Int. Med., 1925, xxxv, 362. The Electrocardiogram as an Aid in the Diagnosis of Adhesive Pericardial Mediastinitis. 